\title{
Initiation of the Breeding Season in a Grazing-Based Dairy by Synchronization of Ovulation
}

\author{
M. C. Cordoba and P. M. Fricke \\ Department of Dairy Science, \\ University of Wisconsin, Madison 53706-1284
}

\begin{abstract}
Lactating dairy cows $(\mathrm{n}=228)$ in a semiseasonal, grazing-based dairy were subjected to artificial insemination (AI) to start the 23-d breeding season (d 0 to 22) followed by natural service (d 23 to 120). Cows were randomly assigned to: 1$)$ Ovsynch $\left(\mathrm{GnRH}, \mathrm{d}-10 ; \mathrm{PGF}_{2 \alpha}\right.$, $\mathrm{d}-3$; $\mathrm{GnRH}, \mathrm{d}-1$; timed AI, d 0 ) followed by AI at estrus (tail paint removal) on $\mathrm{d} 1$ to 22 (Ovsynch; $\mathrm{n}=114$ ); or 2) AI at estrus (tail paint removal) throughout $23 \mathrm{~d}$ of AI breeding (tail paint; $\mathrm{n}=114$ ). Days to first AI service were greater and the 23-d AI service rate was less for tail paint vs. Ovsynch cows $(12.0 \pm 0.6 \mathrm{~d}$ vs. $0 \mathrm{~d}$; and 84.2 vs. $100 \%$, respectively). However, conception to first AI was greater for tail paint vs. Ovsynch cows (47.3 vs. $27.3 \%$, respectively). Cows in the tail paint group received only one AI, during $23 \mathrm{~d}$ of AI, but $46.4 \%$ of Ovsynch cows received a second AI, with similar conception (43.1\%) to that of tail paint cows at first AI (47.3\%). Based on serum progesterone, incomplete luteal regression after $\mathrm{PGF}_{2 \alpha}$, and poor ovulatory responses to $\mathrm{GnRH}$ contributed to lower conception to timed AI in the Ovsynch group. Cumulative pregnancy rates for tail paint and Ovsynch cows did not differ after $23 \mathrm{~d}$ of AI breeding (47.3 vs. $46.3 \%$, respectively) nor after $120 \mathrm{~d}$ of AI/ natural service breeding ( 80.5 vs. $83.3 \%$, respectively). Lactating cows in this grazing-based dairy synchronized poorly to Ovsynch resulting in reduced conception to timed AI compared with AI after tail paint removal. (Key words: Ovsynch, tail paint, grazing, seasonal breeding)
\end{abstract}

Abbreviation key: $\mathbf{P}_{\mathbf{4}}=$ progesterone, $\mathbf{T A I}=$ timed AI.

\section{INTRODUCTION}

To achieve and maintain a seasonal grazing-based dairy in which calving, lactation, and dry periods are relatively synchronous within a herd, the majority of

Received September 25, 2001.

Accepted January 30, 2002.

Corresponding author: P. M. Fricke; e-mail: fricke@calshp.cals. wisc.edu. cows must resume cyclicity and establish pregnancy within $90 \mathrm{~d}$ after calving so that calving and the onset of lactation coincide with the onset of pasture growth during the spring (McDougall et al., 1998). Reproductive inefficiency of lactating dairy cows due to physiologic and environmental factors is the primary limiting factor for establishing and maintaining a seasonal grazing-based dairy system, and few grazing-based dairies in Wisconsin achieve the reproductive efficiency required to maintain a seasonally calving herd. Only $6.3 \%$ of fully intensive grazing-based dairy farms in Wisconsin reported a milking shutdown period during the year in 1995 (Ostrom and Jackson-Smith, 2000). Development of new management strategies to tighten conception and calving periods within a herd is critical to achieving and maintaining seasonal grazing-based dairy systems.

Two reproductive management tools have recently become available for improving reproductive efficiency in lactating dairy cows. The first is Ovsynch, a hormonal protocol for synchronizing ovulation that incorporates a timed AI (TAI; Pursley et al., 1995). We previously assessed synchronization and conception rates for lactating dairy cows on two grazing-based dairies that received TAI after either Ovsynch or a modified Ovsynch protocol (Cordoba and Fricke, 2001). Observed synchronization rates (e.g., ovulation of a follicle within $48 \mathrm{~h}$ of the second GnRH injection) of 84 and $78 \%$ were similar to previously reported rates of 87 (Vasconcelos et al., 2001) and 84\% (Fricke et al., 1998) for lactating dairy cows managed in confinement-based dairies. Similarly, the overall conception rates to TAI of 43.4 and $41.0 \%$ (assessed by ultrasonography at d 32 post TAI) were similar to that previously reported using Ovsynch and TAI in lactating dairy cows in confinement-based dairies (Pursley et al., 1997a, 1997b; Fricke et al., 1998). However, because conception rate was not directly determined for control cows that were bred to a standing estrus in that study, we could not clearly assess the effect of conception rate on cumulative pregnancy rates. Furthermore, the similar cumulative pregnancy rate after $35 \mathrm{~d}$ of breeding of control cows and cows receiving TAI indicated that conception rate might have been greater for control cows bred at a spontaneous estrus 
(Cordoba and Fricke, 2001). Based on these results, we wanted to further assess the use of Ovsynch to induce TAI on the first day of the AI breeding period in grazingbased dairies, especially with regard to conception rate after TAI versus AI to a spontaneous estrus.

The second reproductive management tool is a tail painting system that has recently become commercially available in the United States (Detail Management System; FIL Industries Ltd., Mount Maunganui, New Zealand). The Detail Management System is useful as an aid for estrus detection as well as for overall reproductive management of a grazing-based dairy herd, and may be well suited for use in grazing-based dairy systems in Wisconsin. Tail painting has proven effective as an estrus-detection aid for practical breeding management in New Zealand (Macmillan and Curnow, 1977; Macmillan and Day, 1982; Macmillan et al., 1988, 1998) and in the U.S. (Lucy et al., 1990; Van Cleeff et al., 1996).

We hypothesized that initiation of AI breeding on the first day of the breeding season by Ovsynch followed by $\mathrm{AI}$ after removal of tail paint would result in improved reproductive performance compared with AI after removal of tail paint alone. Our objective was to compare use of Ovsynch to initiate $\mathrm{AI}$ at the onset of the breeding season versus AI after removal of tail paint in a grazingbased dairy system in Wisconsin on interval to first service and on first service conception rate, and to characterize ovarian responses of cows receiving Ovsynch.

\section{MATERIALS AND METHODS}

\section{Animals and Treatments}

This field trial was conducted during the summer of 2000 on a grazing-based dairy farm located in southcentral Wisconsin. The farm comprised approximately 1200 mature dairy cows, 228 of which were assigned to this study. The farm was managed so that a portion of the herd calved seasonally, and the remainder of the herd calved throughout the year and, therefore, was classified as a semiseasonal dairy rather than seasonal. Cows were chosen for this study based on the farm manager's desire to achieve a tight conception pattern for seasonal calving, and because these cows were grazed and milked together throughout the trial as a single group. Cows assigned to this study were milked twice daily and were rotationally grazed on improved grass paddocks throughout the trial. Cows also received supplemental concentrate that was offered twice daily during each milking. Average milk production for cows assigned to this trial was $20 \mathrm{~kg} / \mathrm{d}$ during the study period.

Primiparous $(\mathrm{n}=24)$ and multiparous $(\mathrm{n}=204)$ Holstein $\times$ Brown Swiss and Brown Swiss $x$ Holstein cross- bred dairy cows $(n=228)$ were subjected to a $23-\mathrm{d}$ AI breeding period ( $\mathrm{d} 0$ to 22 ) beginning at the onset of the breeding season (d 0). Mean DIM and lactation number at the onset of the breeding season for cows assigned to this study were $150.5 \pm 5.6$ (range $=50$ to 290 ) and $3.3 \pm 0.1$ (range $=1$ to 6 ), respectively. Ten days before the onset of the breeding season, cows were assigned randomly to each of two treatment groups. Cows were blocked by lactation number and DIM as part of the randomization procedure to minimize confounding of those variables between treatments.

Cows $(n=114)$ in the first group (Ovsynch) received a hormonal protocol for synchronization of ovulation initiated at a random stage of the estrus cycle as described previously (Fricke et al., 1998) using i.m. injections of GnRH (Cystorelin; Merial Ltd., Iselin, NJ) and $\mathrm{PGF}_{2 \alpha}$ (Lutalyse; Pharmacia Animal Health, Kalamazoo, MI), as follows: $\mathrm{d}-10,50 \mu \mathrm{g}$ of $\mathrm{GnRH}$; $\mathrm{d}-3,25 \mathrm{mg}$ of $\mathrm{PGF}_{2 \alpha} ; \mathrm{d}-1,50 \mu \mathrm{g}$ of GnRH. This is a modified Ovsynch protocol using a reduced dosage of GnRH (50 vs. 100 $\mu \mathrm{g})$ per injection that was evaluated in lactating dairy cows in a confinement-based dairy (Fricke et al., 1998). First AI service for cows in the Ovsynch group was conducted as a TAI 12 to $18 \mathrm{~h}$ after the second GnRH injection immediately after the morning milking of the first day of the AI breeding period (d 0; May 19, 2000). Cows $(n=114)$ in the second group (tail paint) received AI during the AI breeding period based on removed tail paint. In addition, cows in the Ovsynch group that were detected in estrus after the initial TAI, received a second AI service after tail paint removal throughout the AI breeding period.

To monitor estrus activity, all cows received tail paint (Detail Estrus-Detection tail paint, New AgriTech, Inc., Little York, NY) after the morning milking at the onset of the AI breeding period (d 0). Briefly, tail paint was applied in a strip $5 \mathrm{~cm}$ wide $\times 20 \mathrm{~cm}$ long over the coccygeal vertebrae of the tail head following the manufacturer's instructions. Each cow was evaluated for evidence of tail paint removal at the afternoon milking. Eleven days after the initial tail painting, additional paint was added as needed to ensure accurate detection of estrus throughout the remainder of the AI breeding period. Cows in which tail paint was removed were considered in estrus and received AI and a fresh application of tail paint within $1 \mathrm{~h}$ after completion of the afternoon milking. Natural service sires were introduced to this group of cows at the end of the AI breeding period (June 10, 2000) and remained with the herd for $14 \mathrm{wk}$ (September 16, 2000). A minimum of six and a maximum of eight natural service sires grazed with this group of cows at any given time during the natural service breeding period. Natural service matings for 
individual cows and bulls were not recorded during the natural service breeding period.

\section{Timed Al and Al after Removal of Tail Paint}

Semen from multiple AI sires was assigned to cows by the herdsman before the start of the AI breeding period. At the time of mating assignment, the herdsman was unaware of the treatment assigned to each cow so that AI sires were randomly distributed between treatments. One professional AI technician from a local AI stud with over 15-yr experience conducted all TAI and AI services throughout the trial. For Ovsynch cows, TAI was conducted immediately after milking on the morning of d 0 over a 3 -h period. All cows were caught in a palpation rail in groups of 12 upon exiting the parlor. Two people in addition to the herdsman assisted the AI technician by determining the correct mating for each cow, locating and thawing straws of semen, and loading and retrieving AI guns. Artificial insemination based on tail paint removal began at the afternoon milking of $d 0$. At each afternoon milking throughout the AI breeding period, cows from both treatment groups in which tail paint was removed were separated from the rest of the herd and placed in a holding pen with ad libitum access to fresh water. The professional AI technician arrived at the farm within $1 \mathrm{~h}$ after the afternoon milking and inseminated cows in which tail paint was removed during the previous 24 -h period.

\section{Body Condition Scoring}

To assess nutritional energy balance and weight loss throughout the trial, BCS was assessed by the same researcher on $d-20$ and 0 , and ranked on a scale from 1 to 5 , where 1 = thin and $5=$ obese (Wildman et al., 1982). Body condition score loss before the AI breeding period was calculated by subtracting BCS at $d-20$ from BCS at d 0 for each cow.

\section{Blood Sampling}

Blood samples were collected from cows via coccygeal venipuncture on $d-20$ and -10 (i.e., $10 \mathrm{~d}$ before the first $\mathrm{GnRH}$ injection and the day of the first $\mathrm{GnRH}$ injection of Ovsynch). In addition, blood samples were collected from cows in the Ovsynch group on $d-3$ (i.e., immediately before injection of $\mathrm{PGF}_{2 \alpha}$ ) and $\mathrm{d}-1$ (i.e., immediately before the second $\mathrm{GnRH}$ injection). Blood samples were allowed to clot for $24 \mathrm{~h}$ at $4^{\circ} \mathrm{C}$, centrifuged $(3000 \times \mathrm{g}$ for $20 \mathrm{~min})$, and serum was collected and stored at $-20^{\circ} \mathrm{C}$ until assayed for progesterone $\left(\mathbf{P}_{4}\right)$ concentrations by ELISA (Rasmussen et al., 1996). Interassay and intraassay coefficients of variation were
12.3 and $6.8 \%$, respectively, using a quality control sample containing $2.5 \mathrm{ng} / \mathrm{ml}$ progesterone.

\section{Assessment of Reproductive Status}

Serum samples collected on $\mathrm{d}-20$ and -10 were classified based on $\mathrm{P}_{4}$ concentrations as either Low ( $\leq 1.0 \mathrm{ng} /$ $\mathrm{ml})$ or High $(>1.0 \mathrm{ng} / \mathrm{ml})$. Cows were grouped into $\mathrm{P}_{4}$ classes based on reproductive status (anovular vs. cycling) immediately before initiation of the first GnRH injection of Ovsynch (Cordoba and Fricke, 2001). Cows with two consecutive low samples (LL) were classified as anovular, whereas cows with two consecutive high samples (HH) or one high and one low sample (HL or LH) were classified as cycling. Because of missing serum samples, some cows were not included in the classification system for reproductive status.

\section{Progesterone $\left(\mathrm{P}_{4}\right)$ Classes}

Cows receiving Ovsynch were grouped into reproductive status classifications based on $\mathrm{P}_{4}$ concentrations of serum samples collected on $d-10$ ( $d$ of the first $\mathrm{GnRH}$ injection), $d-3$ ( $d$ of the $\mathrm{PGF}_{2 \alpha}$ injection), and $\mathrm{d}-1$ (d of the second GnRH injection) of the Ovsynch protocol. Serum samples were classified based on $\mathrm{P}_{4}$ concentrations as either Low $(\leq 1.0 \mathrm{ng} / \mathrm{ml})$ or High $(>1.0 \mathrm{ng} / \mathrm{ml})$, which resulted in eight possible $\mathrm{P}_{4}$ class permutations for Ovsynch cows: HHH, HHL, HLH, HLL, LHH, LHL, LLH, and LLL. Because of missing serum samples, some cows receiving Ovsynch were not included in the $\mathrm{P}_{4}$ classification system.

\section{Pregnancy Diagnosis and Conception Rate}

Visualization of a fluid-filled uterine horn and the presence of a conceptus were used as positive indicators of pregnancy as early as $25 \mathrm{~d}$ after breeding using an ultrasound machine equipped with a transrectal 7.5$\mathrm{MHz}$ linear-array transducer (Aloka 500V; Corometrics Medical Systems, Inc., Wallingford, CT; Fricke et al., 1998). Pregnancy status for all cows was assessed by ultrasonography on d 35 and 49 of the breeding season. Pregnancy status also was determined on d 179 via rectal palpation conducted by the herd veterinarian. Day 35 was chosen to assess conception rate of cows receiving TAI on the first day of the AI breeding period (Ovsynch cows at $35 \mathrm{~d}$ post AI) and any cows receiving AI after removed tail paint during the first $7 \mathrm{~d}$ of the AI breeding period (tail paint cows from 28 to $35 \mathrm{~d}$ post AI). A second ultrasound examination was conducted on d 49 to assess the conception rate of cows receiving AI after tail paint removal during the second and third week of the AI breeding period (i.e., after $23 \mathrm{~d}$ of AI 
breeding; Ovsynch and tail paint cows from 27 to 42 $\mathrm{d}$ post AI). The number of cows diagnosed pregnant expressed as a percentage of cows within that treatment group was defined as the conception rate. Cumulative pregnancy rate was calculated based on results from pregnancy diagnosis conducted after $23 \mathrm{~d}$ of AI breeding (ultrasonography on $\mathrm{d} 49$ post TAI) and after $120 \mathrm{~d}$ of breeding (rectal palpation on d 179 post TAI), and was defined as the total number of pregnant cows expressed as a percentage of the total number of cows within each treatment group. Because dates of natural service matings were not recorded, cumulative pregnancy rates represent pregnancies that were detectable using ultrasound and palpation at the time of pregnancy status evaluation rather than the total number of pregnant cows at $\mathrm{d} 49$ and 179 after the onset of the AI breeding period. Because natural service sires were introduced to the herd at the end of the AI breeding period ( $d$ 23), cumulative pregnancy rate after $120 \mathrm{~d}$ of breeding includes pregnancies resulting from both $\mathrm{AI}$ and natural service breedings. Numbers of cows within each treatment group from which pregnancy status was collected varied due to missing data, which occurred because some cows were not identified during on-farm pregnancy diagnoses or were culled during the course of the experiment.

\section{Statistical Analysis}

Procedure LOGISTIC of SAS (SAS Inst., Inc., Cary, NC) was used to analyze categorical variables, and procedures GLM and MIXED were used to analyze continuous variables. The proportion of cows cycling before the onset of treatments was analyzed with DIM at onset of treatment, BCS at d -20 , and change in BCS from $\mathrm{d}-20$ to 0 as regression variables. The model used to analyze conception and cumulative pregnancy rates included treatment, lactation group ( $1 \mathrm{vs.} \geq 2$ lactations), cycling status before the onset of treatment, and all twoway interactions with treatment, with DIM at onset of the breeding season, BCS at $d-20$, and change in BCS from $d-20$ to 0 as regression variables. The effect of AI sire was not included in this model but was distributed evenly among treatments. The effects of $\mathrm{P}_{4}$ classes on conception rate to TAI was analyzed using procedure LOGISTIC of SAS. Because few cows were classified as HHH $(\mathrm{n}=4)$, HLH $(\mathrm{n}=3), \operatorname{LHH}(\mathrm{n}=5), \operatorname{LLH}(\mathrm{n}=0)$, or LLL $(n=5)$, and because none of those cows conceived to TAI, those classes were excluded from the analysis, and contrasts compared conception rate to TAI for HHL versus HLL cows and HLL versus LHL cows. Treatment effects on other categorical variables were tested by chi-square analysis using the Cochran-MantelHaenszel statistic of SAS. Serum $\mathrm{P}_{4}$ concentrations

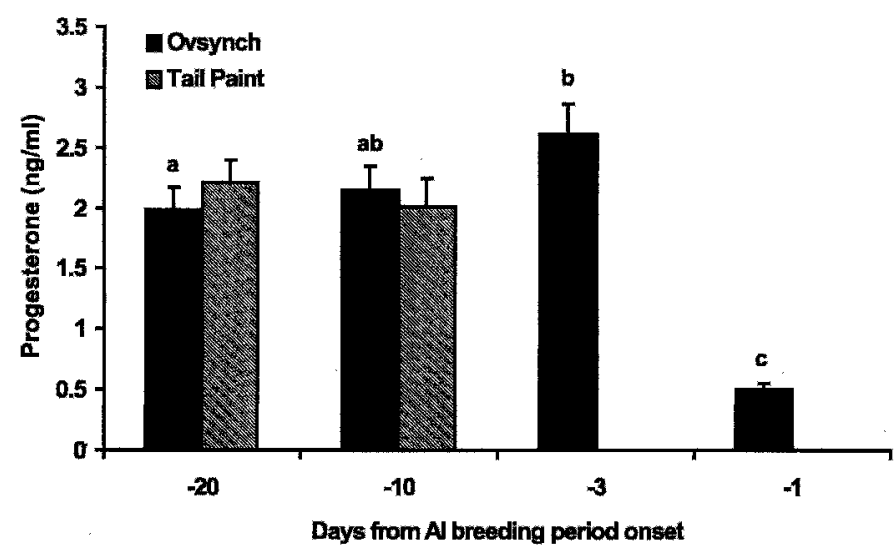

Figure 1. Serum progesterone concentrations (mean \pm SEM) of lactating dairy cows on $\mathrm{d}-20,-10,-3$, and -1 of the experiment (d $0=$ AI breeding period onset). Blood samples were not collected for tail paint cows on $\mathrm{d}-3$ and -1 . Cows in the Ovsynch group received an i.m. injection of $\mathrm{PGF}_{2 \alpha}$ after blood sample collection on $\mathrm{d}-3$. Day effect $(P<0.05)$ for Ovsynch cows is denoted by superscripts. Serum $\mathrm{P}_{4}$ decreased $(P<0.01)$ from $\mathrm{d}-3$ to -1 in response to $\mathrm{PGF}_{2 \alpha}$ for cows receiving Ovsynch.

were analyzed with a repeated measures design using procedure MIXED of SAS, with treatment, day, and treatment $\times$ day interaction included in the model, and differences between specific means were evaluated by using the LSD procedure on least squares means.

\section{RESULTS AND DISCUSSION}

\section{Progesterone Concentrations and Reproductive Status}

Mean serum $\mathrm{P}_{4}$ concentrations were similar for cows in both treatments on $d-20$ and -10 (Figure 1). For Ovsynch cows, mean serum $\mathrm{P}_{4}$ did not differ on $\mathrm{d}-20$, -10 , and -3 , but decreased $(P<0.01)$ on $d-1$, which was $2 \mathrm{~d}$ after $\mathrm{PGF}_{2 \alpha}$ administration (Figure 1). Reproductive status (anovular vs. cycling) was assigned to 86.8\% (99/ 114) of the cows in each treatment group because one or both serum samples (d -20 and/or -10$)$ from 30 cows ( $\mathrm{n}=15 \mathrm{cows} /$ treatment) were missing (Table 1 ). The proportion of anovular cows (low $\mathrm{P}_{4}$ on $\mathrm{d}-20$ and -10 ) did not differ between treatments and was $13.1 \%$ for Ovsynch cows and $17.2 \%$ for tail paint cows (Table 1). Although one study reported that only $3 \%$ of lactating dairy cows were anovular between 56 and 70 DIM (Stevenson et al., 1999), a recent study that included confinement-housed lactating dairy cows from six Midwest U.S. states reported a $28.8 \%$ incidence of anovulation (Pursley et al., 2001). We reported that lactating dairy cows in two grazing-based dairies in Wisconsin exhibited a $29 \%$ incidence of anovulation before the onset of the breeding season using a blood sampling technique 
Table 1. Body condition score loss and DIM at the onset of the AI breeding period for anovular and cycling cows in the Ovsynch and tail paint treatment groups. ${ }^{1}$

\begin{tabular}{|c|c|c|c|c|c|c|}
\hline \multirow[b]{2}{*}{ Reproductive status $^{2}$} & \multirow[b]{2}{*}{ BCS $\operatorname{loss}^{3}$} & \multirow[b]{2}{*}{ Days in milk ${ }^{4}$} & \multicolumn{2}{|c|}{ Ovsynch } & \multicolumn{2}{|c|}{ Tail paint } \\
\hline & & & $\%$ & (no./no.) & $\$$ & (no./no.) \\
\hline Anovular & $0.44 \pm 0.06^{\mathrm{a}}$ & $116.2 \pm 14.8^{\mathrm{a}}$ & 13.1 & $(13 / 99)$ & 17.2 & $(17 / 99)$ \\
\hline Cycling & $0.28 \pm 0.02^{\mathrm{b}}$ & $152.8 \pm 6.0^{\mathrm{b}}$ & 86.9 & $(86 / 99)$ & 82.8 & $(82 / 99)$ \\
\hline \multicolumn{7}{|c|}{${ }^{\mathrm{a}, \mathrm{b}}$ Within a column, means with different superscripts differ $(P<0.05)$. } \\
\hline \multicolumn{7}{|c|}{${ }^{1}$ No treatment difference was detected. } \\
\hline \multirow{2}{*}{\multicolumn{7}{|c|}{$\begin{array}{l}{ }^{2} \text { Serum samples collected on } \mathrm{d}-20 \text { and }-10 \text { were classified based on progesterone concentrations as either } \\
\text { low }(\leq 1.0 \mathrm{ng} / \mathrm{ml}) \text { or high }(>1.0 \mathrm{ng} / \mathrm{ml}) \text {. Cows with two consecutive low samples were classified as anovular; } \\
\text { cows with two consecutive high samples or one high and one low sample were classified as cycling. }\end{array}$}} \\
\hline & & & & & & \\
\hline \multicolumn{7}{|c|}{$\begin{aligned} & { }^{3} \text { Body condition score loss (mean } \pm \text { SEM) was calculated based on BCS assessed on a five-point scale ( } 1 \\
= & \text { emaciated } 5=\text { obese) on } d-20 \text { and } 0 \text { of the experiment. }\end{aligned}$} \\
\hline${ }^{4}$ Average DIM (mea & SEM) at the 0 & I- & & & & \\
\hline
\end{tabular}

similar to that in the present study (Cordoba and Fricke, 2001). Thus, the incidence of anovulation varies widely among herds, is likely greater than previously reported for lactating dairy cows, and may vary from year to year. Further research is required to clarify the nature of anovular conditions in dairy cattle and to develop effective therapies for treating cows exhibiting such conditions.

In cattle, BCS is a subjective estimate of the amount of subcutaneous fat (Edmonson et al., 1989), and cows with a low BCS at calving exhibit poor reproductive performance (Markusfeld et al., 1997). In the present study, mean BCS for all cows was $2.89 \pm 0.03$ at $d-20$, and decreased $(P<0.01)$ to $2.63 \pm 0.03$ at $\mathrm{d} 0$. Although cows experiencing a BCS loss of more than 1 point after parturition experience reduced reproductive performance (Butler and Smith, 1989; Ruegg and Milton, 1995), BCS loss for all cows from $d-20$ to 0 in the present study was moderate $(0.28 \pm 0.02)$. Anovular cows in the present study experienced greater $(P<0.05)$ BCS loss from $d-20$ to 0 and had 37 fewer $(P<0.05)$ DIM at the onset of the AI breeding period compared with cycling cows (Table 1). In a previous study, anestrous cows lost more BW resulting in a more negative energy status than cycling cows, and differences in energy balance among cows was greatest during the first 3 wk postpartum (Staples et al., 1990). Thus, anovular cows in the present study had a shorter period from calving to the onset of the AI breeding period in which to undergo first ovulation and resume postpartum cyclicity, and were likely in a more negative energy status than herdmates with a greater postpartum interval between calving and the onset of the AI breeding period. Although conception rate after Ovsynch is greater for cows with a $\mathrm{BCS} \geq 2.5$ (scale 1 to 5 ) than for cows with a BCS $<2.5$ (Moreira et al., 2000b), no effect of BCS on conception rate to TAI was observed in the present study, possibly due to the relatively good BCS of the cows, the modest BCS losses among cows, and the low incidence of anovular cows in the Ovsynch group.

\section{Reproductive Performance to First Al Service}

Data for conception rate to first AI service from four cows in the Ovsynch group and five cows in the tail paint group were missing because those nine cows were not identified during one of the on-farm pregnancy diagnosis periods. Thus, first service conception rate was assessed for $96.5 \%$ (110/114) of the cows receiving TAI in the Ovsynch group and $94.8 \%$ (91/96) of the cows receiving $\mathrm{AI}$ after tail paint removal in the tail paint group (Table 2).

Submission rate to first AI service during the AI breeding period was greater $(P<0.01)$ for cows receiving Ovsynch compared with cows receiving tail paint (Table 2 ). By design, mean ( \pm SEM) $d$ of the AI breeding period at first AI service for Ovsynch cows was $0.0 \pm 0.0 \mathrm{~d}$ compared with $12.0 \pm 0.6 \mathrm{~d}$ for tail paint cows.

Conception rate to first AI service for tail paint cows receiving AI after tail paint removal was greater $(P<$ 0.01) than that of Ovsynch cows receiving TAI (Table 2). Poor conception rates to Ovsynch were reported in a study conducted on seasonally calving lactating dairy cows in southern Australia in which cows received either Ovsynch or AI to a standing estrus induced using $\mathrm{PGF}_{2 \alpha}$. Pooled conception rate for cows receiving Ovsynch was $38.1 \%$ compared with $65.9 \%$ for cows receiving AI to an induced estrus (Jemmeson, 2000). These results are contrary to initial reports in which conception rates of lactating dairy cows managed in confinement-based dairies receiving Ovsynch were similar to that of cows receiving AI after a standing estrus (Pursley et al., 1997a,b). However, other studies have reported that Ovsynch results in lower conception rates compared with AI after estrus (Stevenson et al., 1999; Jobst et al., 2000). Factors explaining the variation in 
Table 2. Effect of treatment on reproductive performance of lactating dairy cows during the AI breeding period.

\begin{tabular}{|c|c|c|}
\hline \multirow[b]{2}{*}{ Item } & \multicolumn{2}{|c|}{ Treatment group $^{1}$} \\
\hline & Ovsynch & Tail Paint \\
\hline \multicolumn{3}{|l|}{ First AI service } \\
\hline Method of AI & Timed AI & $\mathrm{AI}$ at estrus \\
\hline AI submission rate $(\%)$ & $100.0^{\mathrm{a}}$ & 84.2 \\
\hline $\begin{array}{l}\text { (no./no.) } \\
\text { Mean }( \pm \text { SEM)/Day of AI } \\
\text { breeding period }\end{array}$ & $00+00^{\mathrm{a}}$ & $12.0 \pm 0.6$ \\
\hline $\begin{array}{l}\text { Conception rate }(\%) \\
\text { (no./no.) }\end{array}$ & $\begin{array}{l}27.3^{a^{-}} \\
(30 / 110)\end{array}$ & $\begin{array}{l}47.3 \\
(43 / 91)\end{array}$ \\
\hline \multicolumn{3}{|l|}{ Second AI service } \\
\hline Method of AI & AI at estrus & $\mathrm{AI}$ at estrus \\
\hline $\begin{array}{l}\text { AI submission rate (\%) } \\
\text { (no./no.) }\end{array}$ & $\begin{array}{l}46.4^{\mathrm{a}} \\
(51 / 110)\end{array}$ & $\begin{array}{l}0.0 \\
(0 / 114)\end{array}$ \\
\hline $\begin{array}{l}\text { Mean }( \pm \text { SEM }) / \text { Day of AI } \\
\text { breeding period }\end{array}$ & $17.0 \pm 5.8$ & \\
\hline $\begin{array}{l}\text { Conception rate }(\%) \\
\text { (no./no.) }\end{array}$ & $\begin{array}{l}43.1^{\mathrm{b}} \\
(22 / 51)\end{array}$ & $\cdots$ \\
\hline
\end{tabular}

${ }^{a}$ Different $(P<0.01)$ from tail paint.

${ }^{\mathrm{b}}$ Conception rate for Ovsynch cows receiving AI after tail paint removal (second AI service) did not differ from that of tail paint cows receiving $\mathrm{AI}$ after tail paint removal (first AI service).

${ }^{1}$ Ovsynch cows were managed using synchronization of ovulation (50 $\mu \mathrm{g}$ GnRH, d $-10 ; 25 \mathrm{mg} \mathrm{PGF}{ }_{2 \alpha}, \mathrm{d}-3 ; 50 \mu \mathrm{g} \mathrm{GnRH}, \mathrm{d}-1$ ) and fixed-time AI (d 0) followed by estrus detection and AI after removed tail paint for the remainder of the AI breeding period; tail paint cows were managed using estrus detection and AI after removed tail paint for the duration of the AI breeding period.

conception rate to TAI among herds are unknown at this time but may include the proportion of anovular cows in the herd, the follicular dynamics of individual cows within the herds, or the ability of farm personnel to implement Ovsynch in their herds.

\section{Reproductive Performance to Second Al Service}

No tail paint cows received a second AI service during the AI breeding period, whereas $46.4 \%$ of Ovsynch cows returned to service during the AI breeding period (Table 2). Conception rate to second AI service after tail paint removal for Ovsynch cows was $43.1 \%$, which did not differ from that of tail paint cows at first AI service after tail paint removal (Table 2). Of the 80 Ovsynch cows diagnosed nonpregnant to TAI, 51 returned to service during the AI breeding period resulting in a $63.8 \%$ service rate to second AI service. The disparity in the AI submission rate of $84.2 \%$ to first $\mathrm{AI}$ service for cows in the tail paint group and the $63.8 \%$ return service rate among non-pregnant cows to second AI service in the Ovsynch group may have occurred because the Ovsynch cows were returning to service after TAI, whereas the tail paint cows had not previously received AI. Lactating dairy cows exhibit high rates of embryonic loss after AI (Smith and Stevenson, 1995; Vasconcelos et al., 1997; Fricke et al., 1998). Although

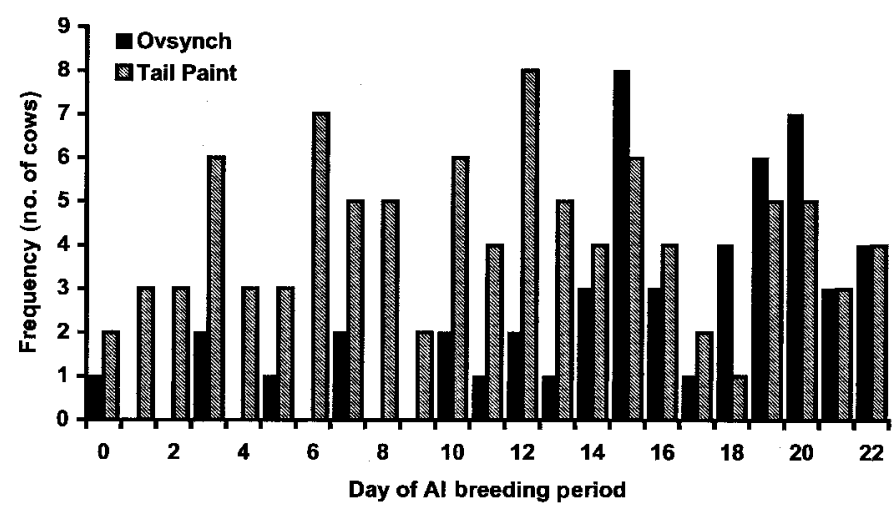

Figure 2. Distribution of the frequency of AI during the AI breeding period based on tail paint removal assessed twice daily at milking. For cows in the Ovsynch group, $\mathrm{AI}$ at the detected estrus represents second AI service, whereas for cows in the tail paint group, AI at the detected estrus represents first AI service.

speculative, it is possible that some of the Ovsynch cows conceived to TAI and subsequently lost those pregnancies near or after the end of the AI breeding period, thereby reducing the number of cows returning to service during the AI breeding period. Also, because 30 pregnant cows are eliminated from among potential Ovsynch cows returning to estrus, the remaining cows may include a biased proportion of cows that are less sexually active.

\section{Distribution of the Frequency of Al During the Al Breeding Period}

The distribution of the frequency of $\mathrm{AI}$ during the $\mathrm{AI}$ breeding period differed between treatments (Figure 2). Cows in the tail paint group received AI based on tail paint removal randomly throughout the AI breeding period, whereas Ovsynch cows showed two peaks of AI activity, one from d 14 to $17(29.4 \% ; 15 / 51$ cows $)$ and the other from d 18 to $22(47.1 \% ; 24 / 51$ cows $)$, post-TAI (Figure 2). One Ovsynch cow received AI after tail paint removal on the afternoon of the day of TAI (d 0). Of the 18 tail paint cows not inseminated during the AI breeding period, $55.6 \%$ (10/18) were anovular, and $44.4 \%$ (8/18) were cycling. Of the 17 anovular tail paint cows, $41.2 \%$ (7/17) received AI after tail paint removal, and $42.9 \%(3 / 7)$ were diagnosed pregnant after $23 \mathrm{~d}$ of AI breeding. Although insemination of anestrous cows during the AI breeding period could be attributed to errors in detecting estrus based on tail paint removal, the observation that those previously anestrous cows conceived to $\mathrm{AI}$ at a similar rate as cyclic cows indicates that some of the anestrous cows reinitiated postpartum ovarian activity after $\mathrm{d}-10$ but before the end of the AI breeding period. 
Table 3. Frequency distribution, anovular cows, conception rate to TAI, and cows returning to AI service during the AI breeding period for cows receiving Ovsynch based on serum $\mathrm{P}_{4}$ concentrations collected on $\mathrm{d}$ $-10,-3$, and -1 of the experiment (d $0=\mathrm{TAI})$.

\begin{tabular}{|c|c|c|c|c|c|c|c|}
\hline \multirow[b]{2}{*}{$\mathrm{P}_{4}$-class ${ }^{1}$} & \multirow[b]{2}{*}{$\mathrm{n}$} & \multirow{2}{*}{$\begin{array}{l}\text { Anovular } \\
\text { cows } \\
\% \text { (no.) }\end{array}$} & \multirow{2}{*}{$\begin{array}{l}\text { Conception } \\
\text { rate }^{3} \\
\% \text { (no.) }\end{array}$} & \multirow{2}{*}{$\begin{array}{l}\text { Cows } \\
\text { returning } \\
\text { to service } \\
\% \text { (no.) }\end{array}$} & \multicolumn{3}{|c|}{$\begin{array}{l}\text { Day of AI breeding } \\
\text { period at AI (no.) }\end{array}$} \\
\hline & & & & & $0-13$ & $14-17$ & $18-22$ \\
\hline \multicolumn{8}{|c|}{ High $\mathrm{P}_{4}$ at $\mathrm{d}-1$} \\
\hline HHH & 4 & $0.0(0)$ & $0.0(0)$ & $100.0(4)$ & 0 & 2 & 2 \\
\hline LHH & 5 & $0.0(0)$ & $0.0(0)$ & 60.0 & 1 & 2 & 0 \\
\hline HLH & 3 & $0.0(0)$ & $0.0(0)$ & 100.0 & 0 & 3 & 0 \\
\hline LLH & 0 & $0.0(0)$ & $0.0(0)$ & $0.0(0)$ & 0 & 0 & 0 \\
\hline$\Sigma$ & 12 & $0.0(0)$ & $0.0(0)$ & $83.3(10)$ & 1 & 7 & 2 \\
\hline \multicolumn{8}{|c|}{ Low $\mathrm{P}_{4}$ at $\mathrm{d}-1$} \\
\hline LLL & 5 & 80.0 & $0.0(0)$ & 60.0 & 2 & 1 & 0 \\
\hline HLL & 28 & $0.0(0)$ & $14.3^{\mathrm{a}}(4)$ & $71.4(20)$ & 3 & 6 & 11 \\
\hline LHL & 33 & $24.2(8)$ & $39.4^{\mathrm{b}}(13)$ & $27.3(9)$ & 2 & 0 & 7 \\
\hline HHL & 23 & $0.0(0)$ & $43.5^{\mathrm{b}}(10)$ & $30.4(7)$ & 3 & 0 & 4 \\
\hline$\Sigma$ & 89 & $13.5(12)$ & $30.3(27)$ & 43.8 (39) & 10 & 7 & 22 \\
\hline Overall & 101 & $11.9(12)$ & $26.7(27)$ & $48.5(49)$ & 11 & 14 & 24 \\
\hline
\end{tabular}

${ }^{\mathrm{a}, \mathrm{b}}$ Within a column, different superscripts denote significant contrasts $(P<0.05)$. Due to small cell sizes, cows classified as HHH, LHH, HLH, LLH, and LLL were excluded from the statistical analysis for conception rate to TAI.

${ }^{1}$ Combinations of highs $(\mathrm{H} ;>1 \mathrm{ng} / \mathrm{ml})$ and lows $(\mathrm{L} ; \leq 1 \mathrm{ng} / \mathrm{ml})$ represent serum progesterone $\left(\mathrm{P}_{4}\right)$ concentrations at $\mathrm{d}-10$ (first $\mathrm{GnRH}$ injection), -3 ( $\mathrm{PGF}_{2 \alpha}$ injection), and -1 (second $\mathrm{GnRH}$ injection) of Ovsynch.

${ }^{2}$ Serum samples collected on $\mathrm{d}-20$ and -10 were classified based on $\mathrm{P}_{4}$ concentration as either low $(\leq 1.0$ $\mathrm{ng} / \mathrm{ml})$ or high $(>1.0 \mathrm{ng} / \mathrm{ml})$. Cows with two consecutive low samples were classified as anovular; cows with two consecutive high samples or one high and one low sample were classified as cyclic.

${ }^{3}$ Proportion of cows diagnosed pregnant to TAI (ultrasonography at $35 \mathrm{~d}$ post TAI).

${ }^{4}$ Cows returning to service during the AI breeding period (percentage of nonpregnant cows).

\section{Progesterone Classes}

Successful synchronization to the Ovsynch protocol involves synchronizing growth of a new follicular wave at the onset of the protocol (controlled by the first $\mathrm{GnRH}$ injection on $\mathrm{d}-10$ ), synchronization of luteal regression (induced by $\mathrm{PGF}_{2 \alpha}$ on $\mathrm{d}-3$ ), and synchronization of ovulation (induced by $\mathrm{GnRH}$ on $\mathrm{d}-1$ ). The stage of the estrous cycle when Ovsynch is initiated also affects synchronization and conception rate to the Ovsynch protocol in both lactating dairy cows (Vasconcelos et al., 2001) and dairy heifers (Moreira et al., 2000a). Cows receiving Ovsynch in the present study were assigned to $\mathrm{P}_{4}$ classes and were separated and summed as two groups: those $\mathrm{P}_{4}$ classes with high $\mathrm{P}_{4}$ at $\mathrm{d}-1$ ( $\mathrm{HHH}$, LHH, HLH, and LLH) and those with low $\mathrm{P}_{4}$ at $\mathrm{d}-1$ (LLL, HLL, LHL, and HHL). Only 91.8\% (101/110) of the Ovsynch cows with a known pregnancy status at $d$ 35 were assigned to $\mathrm{P}_{4}$ classes because one or more serum samples from nine cows receiving Ovsynch were missing on $\mathrm{d}-10,-3$, and/or -1 (Table 3 ).

The $\mathrm{P}_{4}$ classes were used to estimate the stage of the cycle at initiation of Ovsynch, response to the first GnRH injection, and luteolysis in response to $\mathrm{PGF}_{2 \alpha}$ for cows receiving the Ovsynch protocol similar to the method described by Moreira et al. (2001) but with some modifications. Unfortunately, these estimates are speculative because multiple ultrasound scans and es- trus expression before initiation of treatments were not evaluated in the present study. In addition, the day of the AI breeding period at return AI service for Ovsynch cows returning to service was used to further analyze the response to Ovsynch. Of the 51 Ovsynch cows returning to estrus during the AI breeding period (Table 2 ), one cow returning to estrus on $d 15$ and one cow returning to estrus on $\mathrm{d} 18$ were not assigned to a $\mathrm{P}_{4}$ class due to missing serum samples (Table 3). The 49 cows returning to estrus that were assigned to a $\mathrm{P}_{4}$ class were grouped into one of three return periods (d 0 to 13,14 to 17 , or 18 to 22 ; Table 3 ) based on the two peak periods of return service activity exhibited by Ovsynch cows from d 14 to 17 and d 18 to 22 and those Ovsynch cows receiving AI service before d 14 (Figure 2).

\section{Ovsynch Cows With High Progesterone at d -1}

Ovsynch cows with high $\mathrm{P}_{4}$ at $\mathrm{d}-1$ failed to synchronize luteal function in response to the Ovsynch protocol and, therefore, failed to conceive to the Ovsynch protocol. Of the 101 Ovsynch cows assigned to a $\mathrm{P}_{4}$ class, $12.0 \%$ had high $\mathrm{P}_{4}$ at $\mathrm{d}-1$ with four $\mathrm{HHH}$ cows, five LHH cows, three HLH cows, and zero LLH cows. None of these cows was anovular, none was diagnosed pregnant at $d 35$, and $83.3 \%$ returned to service during the 
AI breeding period (Table 3). Of the 10 cows returning to service, most $(n=7)$ returned on $d 14$ to 17 , one cow returned on $\mathrm{d} 6$, and the other two cows returned on $\mathrm{d}$ 18 and 22 after TAI.

The four HHH cows were likely diestrus or early proestrus at the time of the first GnRH injection, and these cows likely failed to undergo luteolysis because their GnRH-induced CL were not yet responsive to $\mathrm{PGF}_{2 \alpha} 7 \mathrm{~d}$ after $\mathrm{GnRH}$ (Wiltbank et al., 1995) and failed to completely regress (Moriera et al., 2000a), resulting in high $\mathrm{P}_{4}$ at $\mathrm{d}-1$. It is possible that some cows receiving Ovsynch ovulate smaller follicles compared with cows ovulating after a spontaneous estrus due to administration of GnRH after acquisition of ovulatory capacity but before the final stages of follicular maturity. Ovulation of smaller follicles results in smaller CL that produce less $\mathrm{P}_{4}$ (Vasconcelos et al., 2001) and perhaps exhibit a delayed responsiveness to $\mathrm{PGF}_{2 \alpha}$ due to expression of fewer $\mathrm{PGF}_{2 \alpha}$ receptors. Incomplete luteal regression has been reported in lactating dairy cows receiving Ovsynch, with $7 \%$ of cows exhibiting high $(>2.0 \mathrm{ng} / \mathrm{ml}) \mathrm{P}_{4}$ $48 \mathrm{~h}$ after $\mathrm{PGF}_{2 \alpha}$ (Moreira et al., 2001). Furthermore, $8 \%$ of lactating dairy cows in New Zealand failed to exhibit estrus after $\mathrm{PGF}_{2 \alpha}$ administration, and the estrous response tended to increase as the cycle advanced from $\mathrm{d} 8$ to 15 , indicating that some cows receiving $\mathrm{PGF}_{2 \alpha}$ early during the cycle exhibited incomplete luteal regression (Macmillan and Henderson, 1984). All four of these $\mathrm{HHH}$ cows were diagnosed nonpregnant at $\mathrm{d} 35$ and returned to service during the AI breeding period.

The LHH cows were possibly in metestrus at the time of the first $\mathrm{GnRH}$ injection and administration of $\mathrm{PGF}_{2 \alpha}$ $7 \mathrm{~d}$ later likely regressed the CL that ovulated after the previous estrus but failed to regress the younger GnRH-induced CL similar to that observed for $\mathrm{HHH}$ cows. None of these cows was diagnosed pregnant at $d$ 35 , and three of the five cows returned to service during the AI breeding period. The HLH cows were likely in late diestrus to proestrus at the time of the first GnRH injection and failed to ovulate a follicle in response to $\mathrm{GnRH}$, as evidenced by low $\mathrm{P}_{4}$ concentrations $7 \mathrm{~d}$ later at the $\mathrm{PGF}_{2 \alpha}$ injection. All three $\mathrm{HLH}$ cows returned to service during the AI breeding period on d 16. Assuming an estrous cycle duration of $21 \mathrm{~d}$, HLH cows would have received the first GnRH injection of the Ovsynch protocol between $\mathrm{d} 15$ and 17 of the estrous cycle. Because of the lack of ovulation to the first GnRH injection, asynchrony between the TAI and ovulation occurred due to spontaneous regression of the CL and premature estrous expression and ovulation before the second GnRH injection. In a previous study, all dairy heifers initiating the Ovsynch protocol on d 15 of the estrous cycle were observed in estrus before the second GnRH injection, whereas no estrous behavior was observed when the protocol was initiated on $\mathrm{d} 2,5,10$, or 18 of the estrous cycle (Moreira et al., 2000a). For heifers exhibiting three follicular waves, $d 15$ to 17 of the cycle coincides with emergence of the third follicular wave (Ginther et al., 1996), when the dominant follicle of the second wave has lost ovulatory capacity, and a follicle from the third wave has not yet undergone deviation and acquired ovulatory capacity (Sartori et al., 2001). By contrast, heifers exhibiting two follicular waves exhibit a dominant follicle with ovulatory capacity at this time (Ginther et al., 1996) and would not exhibit premature estrus and ovulation due to the presence of $\mathrm{P}_{4}$ from a GnRH-induced CL.

It is also possible that the reduced dose of $\mathrm{GnRH}$ used in the present study $(50 \mu \mathrm{g})$ may have reduced the ovulatory response to $\mathrm{GnRH}$ compared with other studies that have used the labeled dose of GnRH (100 $\mu \mathrm{g})$. However, reducing the dose of GnRH does not compromise synchronization or conception rates to Ovsynch in confinement-housed lactating Holstein cows (Fricke et al., 1998). Synchronization and conception rate using the reduced dose of $\mathrm{GnRH}$ in lactating dairy cows managed in two grazing-based dairies in Wisconsin yielded similar results to that reported for lactating cows in confinement-based dairies (Cordoba and Fricke, 2001). Furthermore, a 50- $\mu$ g dose of GnRH induced an LH response similar to that of a 100- $\mu \mathrm{g}$ dose, and both doses were equally efficacious for treating ovarian follicular cysts in dairy cows (Seguin et al., 1976), indicating that $50 \%$ of the recommended dose of GnRH may effectively ovulate normally growing, noncystic follicles during the Ovsynch protocol. Collectively, these data support that HLH cows may have exhibited three-wave cycles which, along with the stage of the estrous cycle at which Ovsynch was initiated and the incomplete luteal regression after $\mathrm{PGF}_{2 \alpha}$, contributed to their lack of synchrony to the Ovsynch protocol. In support of this notion, a comparative study between US Holstein cows managed in confinement dairies and New Zealand Friesian lactating dairy cows managed in grazing-based dairies showed that follicular turnover occurred earlier in the New Zealand cows (Bilby et al., 1998), suggesting a greater proportion of New Zealand cows exhibited three follicular waves.

\section{Ovsynch Cows With Low Progesterone at d -1}

Ovsynch cows with low $\mathrm{P}_{4}$ at $\mathrm{d}-1$ had no functional $\mathrm{CL}$ at the second GnRH injection, and these $\mathrm{P}_{4}$ classes comprised all anovular cows and those cows that were successfully synchronized by the Ovsynch protocol. Of the 101 Ovsynch cows assigned to a $\mathrm{P}_{4}$ class, $88.1 \%$ had low $\mathrm{P}_{4}$ at $\mathrm{d}-1,13.5 \%$ of these cows were anovular, 
$30.3 \%$ of these cows were diagnosed pregnant at d 35 , and $43.8 \%$ returned to service during the $\mathrm{AI}$ breeding period (Table 3 ). Of the 39 cows returning to service, 10 cows returned on $\mathrm{d} 0$ to 13,7 cows returned on $d 14$ to 17 , and 22 cows returned on d 18 to 22 . Cows with low $\mathrm{P}_{4}$ at $\mathrm{d}-1$ comprised 5 LLL cows, 28 HLL cows, 33 LHL cows, and 23 HHL cows.

None of the five LLL cows conceived, and three of five LLL cows returned to estrus during the AI breeding period. Four of five LLL cows were anovular, and one of the anovular cows returned to estrus during the AI breeding period. Anovular cows that failed to ovulate in response to the first GnRH injection would have exhibited this $\mathrm{P}_{4}$ profile, and it is possible that the one anestrous cow returning to service could have reinitiated ovarian activity after $\mathrm{d}-10$ but before the end of the AI breeding period as exhibited by some of the anovular tail paint cows. It is unclear why the one cyclic cow (high $\mathrm{P}_{4}$ on $\mathrm{d}-20$ ) in this $\mathrm{P}_{4}$ class would have had low $\mathrm{P}_{4}$ on all of the other sampling days.

The 28 HLL cows were likely proestrus at the time of the first GnRH injection and failed to ovulate a follicle in response to $\mathrm{GnRH}$ as evidenced by low $\mathrm{P}_{4}$ concentrations $7 \mathrm{~d}$ later at the $\mathrm{PGF}_{2 \alpha}$ injection. Some of these HLL cows would have received the first GnRH injection of the Ovsynch protocol around d 15 to 17 of the cycle and failed to ovulate a follicle, resulting in asynchrony between the TAI and ovulation similar to that described for HLH cows. The six cows returning to service from d 14 to 17 likely represent this physiologic scenario. It is also possible that some of the HLL cows failed to ovulate to the first GnRH injection and received their second GnRH injection around the time of spontaneous estrus. These cows would have either conceived to the TAI or returned to estrus at a normal cycle length approximately 18 to $22 \mathrm{~d}$ later, and the 11 cows returning to service from d 18 to 22 likely represent this physiologic scenario. None of the HLL cows were anovular, and $71.4 \%$ returned to service during the AI breeding period.

Conception rate to TAI for HLL cows was $14.3 \%$, which was lower $(P<0.05)$ than that of LHL and HHL cows. The low conception rate of cows exhibiting the HLL $\mathrm{P}_{4}$ profile contributed significantly to the overall reduction in conception rate to TAI observed in the present study. Had the 28 Ovsynch cows assigned to this $\mathrm{P}_{4}$ class exhibited a $40 \%$ conception rate to TAI, similar to LHL and HLL cows, the overall conception rate to TAI for Ovsynch cows would have increased from 27 to $34 \%$, a conception rate similar to that reported previously for cows receiving Ovsynch but lower than that of cows receiving AI after a standing estrus (Stevenson et al., 1999; Jobst et al., 2000). It is possible that a population of cows in the present study may have responded poorly to $\mathrm{GnRH}$ administered during the latter stages of a three-wave cycle as discussed previously for both the HLH and HLL cows. High producing lactating dairy cows primarily exhibit two follicular waves during an estrous cycle (Taylor and Rajamahendran, 1991; Sartori et al., 2000), whereas follicular turnover occurs more rapidly in nonlactating dairy heifers (Pursley et al., 1995), which exhibit more three- and fourwave cycles (Savio et al., 1988; Sartori et al., 2000). Although both lactating dairy cows and dairy heifers experience follicular synchrony problems when initiating Ovsynch during the latter stages of the estrous cycle (Moreira et al., 2000a; Vasconcelos et al., 2001), the degree of asynchrony is greater in dairy heifers because, as a population, they exhibit more rapid turnover of follicular waves (Pursley et al., 1995). Thus, cows exhibiting cycles with two follicular waves and initiating Ovsynch during the latter stages of the estrous cycle would more frequently exhibit the HHL $\mathrm{P}_{4}$ profile and higher conception rates because of the greater likelihood of ovulation in response to the first GnRH injection which would prevent premature ovulation and asynchrony with TAI. By contrast, cows exhibiting cycles with three or more follicular waves and initiating Ovsynch during the latter stages of the estrous cycle would more frequently exhibit the HLL $\mathrm{P}_{4}$ profile and lower conception rates to TAI because of the greater likelihood of ovulation failure to the first $\mathrm{GnRH}$ injection resulting in asynchrony between ovulation and TAI. Indeed, presynchronization of lactating dairy cows in confinementbase dairies with two injections of $\mathrm{PGF}_{2 \alpha}$ before initiation of Ovsynch increased conception rate perhaps by moving cows into a more favorable stage of the estrous cycle at initiation of the first GnRH injection (Moreira et al., 2001). As mentioned previously, a greater proportion of New Zealand cows may exhibit three rather than two follicular waves (Bilby et al., 1998). Further data on the patterns of follicular growth in cows managed in grazing-based systems are needed to confirm this notion for the poor response to Ovsynch observed in the present study.

Anovular cows constituted $24.2 \%$ of the 33 LHL cows, and $37.5 \%$ (3/8) of the anovular cows were diagnosed pregnant to TAI. The responses of these anovular cows to Ovsynch demonstrate the effectiveness of GnRH for inducing ovulation in anovular dairy cows similar to that reported previously (Archbald et al., 1990; Stevenson et al., 1999). Although the blood sampling technique used to determine anovulation in the present study did not allow for classification of anovular cows based on ovarian morphology, Ovsynch has been shown to induce pregnancy in cows exhibiting ovarian cysts (Fricke and Wiltbank, 1999; Bartolome et al., 2000), a common physiologic manifestation of the anovulatory condition 
in dairy cattle (Garverick, 1997). The LHL $\mathrm{P}_{4}$ class also included proestrous cows that synchronized follicular and luteal function in response to the Ovsynch protocol. Conception rate to TAI for cows in this $\mathrm{P}_{4}$ class was $39.4 \%$, which was similar to HHL cows but greater $(P$ $<0.05$ ) than that of HLL cows. The conception rate of LHL cows in this study is similar to that reported by Ovsynch in lactating dairy cows in confinement-based dairies (Pursley et al., 1997a,b; Fricke et al., 1998). Of the cows in this $\mathrm{P}_{4}$ class, $27.3 \%$ returned to estrus during the AI breeding period, and two of these cows were anovular. It is not known why the percentage of nonpregnant LHL and HHL cows returning to service (45.0 and $53.8 \%$, respectively) during the AI breeding period was lower than that of HLL cows (83.3\%), but this phenomenon occurred for both anovular and cycling cows in the LHL $\mathrm{P}_{4}$ class. The seven cows returning to service on d 18 to 22 likely synchronized follicular and luteal function in response to the Ovsynch protocol but failed to conceive to the TAI.

The 23 HHL cows included diestrous and early proestrous cows that synchronized follicular and luteal function to the Ovsynch protocol. Conception rate to TAI for cows in this $\mathrm{P}_{4}$ class was $43.5 \%$, which was similar to LHL cows but greater $(P<0.05)$ than that of HLL cows. As discussed for LHL cows, the conception rate of HHL cows is similar to that previously reported using Ovsynch in lactating dairy cows in confinement-based dairies (Pursley et al., 1997a, 1997b; Fricke et al., 1998). There were no anovular cows assigned to this $\mathrm{P}_{4}$ class, and $30.4 \%$ of the cows in this $\mathrm{P}_{4}$ class returned to estrus during the AI breeding period. The poor return rate of HHL cows compared with HLL cows is an interesting observation but cannot be explained by the current results. The four cows that returned to service on $d 18$ to 22 likely synchronized follicular and luteal function in response to the Ovsynch protocol but failed to conceive to the TAI.

\section{Cumulative Pregnancy Rates}

Cumulative pregnancy rate for Ovsynch and tail paint cows was similar after $23 \mathrm{~d}$ of AI breeding (ultrasonography at $\mathrm{d} 49$ ) and after $120 \mathrm{~d}$ of AI/natural service breeding (rectal palpation at d 179; Table 4). Two cows in the Ovsynch group that were diagnosed pregnant at the ultrasound examination on d 35 (i.e., to TAI) were diagnosed nonpregnant at the ultrasound examination on d 49 (i.e., after $23 \mathrm{~d}$ of AI breeding).

In contrast to Ovsynch, the tail paint system used in the present study resulted in excellent reproductive performance. Submission rate to first AI service during the $\mathrm{AI}$ breeding period was $84.2 \%$, with a first $\mathrm{AI}$ service conception rate of $47.3 \%$. In a previous study in New
Table 4. Effect of treatment on cumulative pregnancy rate after 23 $\mathrm{d}$ of $\mathrm{AI}$ breeding and after $120 \mathrm{~d}$ of $\mathrm{AI} /$ natural service breeding.

\begin{tabular}{|c|c|c|c|c|}
\hline \multirow[b]{3}{*}{ Cumulative pregnancy rate $^{2}$} & \multicolumn{4}{|c|}{ Treatment group ${ }^{1}$} \\
\hline & \multicolumn{2}{|c|}{ Ovsynch } & \multicolumn{2}{|c|}{ Tail Paint } \\
\hline & $\%$ & (no./no.) & $\%$ & $($ no./no.) \\
\hline $\begin{array}{l}\text { After } 23 \mathrm{~d} \text { of AI breeding } \\
\text { After } 120 \mathrm{~d} \text { of } \mathrm{AI} / \text { natural }\end{array}$ & 46.3 & $(50 / 108)$ & 47.3 & $(43 / 91)$ \\
\hline service breeding & 83.3 & $(80 / 96)$ & 80.5 & $(66 / 82)$ \\
\hline
\end{tabular}

${ }^{1}$ No treatment differences were detected.

${ }^{2}$ Number of cows diagnosed pregnant after $23 \mathrm{~d}$ of AI breeding (ultrasonography $49 \mathrm{~d}$ after the first day of the AI breeding period) or after $120 \mathrm{~d}$ of breeding (rectal palpation $179 \mathrm{~d}$ after the first day of the AI breeding period), expressed as a percentage of cows within that treatment group.

Zealand, $94.5 \%$ of synchronized dairy heifers were detected in estrus using a tail paint system (Macmillan et al., 1988). Tail paint resulted in similar cumulative pregnancy rates after 24 and $120 \mathrm{~d}$ of breeding compared with use of Ovsynch to initiate TAI at the onset of the AI breeding period. Results from the present study indicate that Ovsynch is not an effective reproductive management tool for lactating dairy cows managed in grazing-based dairies due to the poor conception rate to TAI. Further research is needed to develop protocols that effectively synchronize ovulation in lactating dairy cows that respond poorly to Ovsynch.

Finally, although cumulative pregnancy rate after $120 \mathrm{~d}$ of breeding did not differ between treatment groups, the cumulative pregnancy rate of $82 \%$ across both treatment groups was low for this stage of the breeding season. By comparison, cumulative pregnancy rate after only $56 \mathrm{~d}$ of breeding was nearly $82 \%$ for dairy cows in Australia (Jemmeson, 2000). Introduction of natural service sires after the 23-d AI breeding period in the present study increased the number of pregnancies in this group of cows by only $35 \%$. Although factors responsible for the poor reproductive performance observed in the present study are not known, heat stress can affect reproductive performance in cows by affecting both oocyte quality during the periovulatory period and increasing early embryonic loss (Hansen et al., 1992). Heat stress also impairs fertility of natural service sires by decreasing sperm concentration, lowering sperm motility, and increasing the percentage of morphologically abnormal sperm in an ejaculate (Barth and Bowman, 1994). We have previously implicated heat stress as a factor for poor reproductive performance in grazingbased dairies during natural service breeding in a previous field trial in Wisconsin during the summer breeding period (Cordoba and Fricke, 2001). Official temperature data (Midwestern Climate Center, Champaign, IL) were collected from a research station located within 10 
miles of this farm (Dodgeville, WI; Station ID: 472173). Although the mean maximum daily temperature was relatively cool during the AI breeding period $\left(69.4^{\circ} \mathrm{F}\right)$, reported high maximum temperatures during the trial were $82,86,84,88$, and $92^{\circ} \mathrm{F}$ for the months of May, June, July, August, and September 2000, respectively.

\section{CONCLUSIONS}

Conception rate to TAI of lactating dairy cows in this grazing-based dairy receiving Ovsynch at first service was lower than that of cows receiving AI after tail paint removal at first service. Progesterone profiles of Ovsynch cows indicated that incomplete luteal regression after $\mathrm{PGF}_{2 \alpha}$ and poor ovulatory responses to $\mathrm{GnRH}$ related to the stage of the cycle at initiation of Ovsynch contributed to the poor reproductive performance of cows in this grazing-based dairy receiving Ovsynch. Furthermore, despite the improved AI submission rate during the AI breeding period, Ovsynch did not improve cumulative pregnancy rate after $23 \mathrm{~d}$ of AI breeding or after $120 \mathrm{~d}$ of $\mathrm{AI} /$ natural service breeding compared with use of tail paint to initiate AI breeding. Results from the present study indicate that Ovsynch is not an effective reproductive management tool for lactating dairy cows managed in grazing-based dairies. However, variation in the response to Ovsynch may occur across herds under various management systems and physiologic scenarios. Further research is needed to understand the underlying causes for variation among herds in responsiveness to Ovsynch and to develop protocols that effectively synchronize ovarian function in lactating dairy cows that respond poorly to Ovsynch.

\section{ACKNOWLEDGMENTS}

The authors thank Opitz dairy for use of their animals and facilities, Pharmacia Animal Health, Kalamazoo, MI, for providing Lutalyse, and Merial, Ltd., for providing Cystorelin. This research was supported by Hatch project WIS04222 to P.M.F.

\section{REFERENCES}

Archbald, L. F, S. N. Norman, E. L. Bliss, T. Tran, S. Lyle, P. G. A. Thomas, and A. C. Rathwell. 1990. Incidence and treatment of abnormal postpartum ovarian function in dairy cows. Theriogenology 34:283-290.

Barth, A. D., and P. A. Bowman. 1994. The sequential appearance of sperm abnormalities after scrotal insulation or dexamethasone treatment in bulls. Can. Vet. J. 35:93-102.

Bartolome, J. A., L. F. Archbald, P. Morresey, J. Hernandez, T. Tran, D. Kelbert, K. Long, C. A. Risco, and W. W. Thatcher. 2000. Comparison of synchronization of ovulation and induction of estrus as therapeutic strategies for bovine ovarian cysts in the dairy cow. Theriogenology. 53:815-825.

Bilby, C. R., K. L. Macmillan, G. A. Verkerk, J. A. Peterson, A. T. Koenigsfeld, and M. C. Lucy. 1998. A comparative study of ovarian function in American (U.S.) Holstein and New Zealand (NZ) Friesian lactating dairy cows. J. Dairy Sci. 81(Suppl. 1):222. (Abstr.)

Butler, W. R., and R. D. Smith. 1989. Interrelationships between energy balance and postpartum reproductive function in dairy cattle. J. Dairy Sci. 72:767-783.

Cordoba, M. C., and P. M. Fricke. 2001. Evaluation of two hormonal protocols for synchronization of ovulation and timed artificial insemination in dairy cows managed in grazing-based dairies. J. Dairy Sci. 84:2700-2708.

Edmonson, A. J., I. J. Lean, L. D. Weaver, T. Farver, and G. Webster. 1989. A body condition scoring chart of Holstein dairy cows. J. Dairy Sci. 72:68-78.

Fricke, P. M., J. N. Guenther, and M. C. Wiltbank. 1998. Efficacy of decreasing the dose of GnRH used in a protocol for synchronization of ovulation and timed AI in lactating dairy cows. Theriogenology 50:1275-1284.

Fricke, P. M., and M. C. Wiltbank. 1999. Effect of milk production on the incidence of double ovulation in dairy cows. Theriogenology 52:1133-1143.

Garverick, H. A. 1997. Ovarian follicular cysts in dairy cows. J. Dairy Sci. 80:995-1004.

Ginther, O. J., M. C. Wiltbank, P. M. Fricke, J. R. Gibbons, and K. Kot. 1996. Minireview. Selection of the dominant follicle in cattle. Biol. Reprod. 55:1187-1194.

Hansen, P. J., W. W. Thatcher, and A. D. Ealy. 1992. Methods for reducing effects of heat stress on pregnancy. Pages 116-125 in Large Dairy Herd Management. H. H. Van Horn and C. J. Wilcox, ed. Am. Dairy Sci. Assoc., Champaign, IL.

Jemmeson, A. 2000. Synchronising ovulation in dairy cows with either two treatments of gonadotropin-releasing hormone and one of prostaglandin, or two treatments of prostaglandin. Aust. Vet. J. 78:108-111.

Jobst, S. M., R. L. Nebel, M. L. McGilliard, and K. D. Pelzer. 2000. Evaluation of reproductive performance in lactating dairy cows with prostaglandin $\mathrm{F}_{2 \alpha}$, gonadotropin-releasing hormone, and timed artificial insemination. J. Dairy Sci. 83:2366-2372.

Lucy, M. C., W. W. Thatcher, and K. L. Macmillan. 1990. Ultrasonic identification of follicular populations and return to estrus in early postpartum dairy cows given intravaginal progesterone for 15 days. Theriogenology 34:325-340.

Macmillan, K. L., and R. J. Curnow. 1977. Tail painting-a simple form of oestrus detection in New Zealand dairy herds. New Zealand J. Exp. Ag. 5:357-361.

Macmillan, K. L., and A. M. Day. 1982. Prostaglandin $\mathrm{F}_{2 \alpha}$-a fertility drug in dairy cattle? Theriogenology 18:245-253.

Macmillan, K. L., and H. V. Henderson. 1984. Analyses of the variation in the interval from an injection of prostaglandin $\mathrm{F}_{2 \alpha}$ to oestrus as a method of studying patterns of follicle development during dioestrus in dairy cows. Anim. Reprod. Sci. 6:245-254.

Macmillan, K. L., V. K. Taufa, D. R. Barnes, A. M. Day, and R. Henry. 1988. Detecting estrus in synchronized heifers using tail paint and an aerosol raddle. Theriogenology 30:1099-1114.

Markusfeld, O., N. Galon, and E. Ezra. 1997. Body condition score, health, yield, and fertility in dairy cows. Vet. Rec. 141:67-72.

McDougall, S., K. L Macmillan, and N. B. Williamson. 1998. Factors associated with prolonged period of post partum anoestrum in pasture-fed dairy cattle. Proc. XX World Buiatrics Congr. Vol. 2, Pages 657-662.

Moreira, F., R. L. de la Sota, T. Diaz, and W. W. Thatcher. 2000a. Effect of day of the estrous cycle at the initiation of a timed artificial insemination protocol on reproductive responses in dairy heifers. J. Anim. Sci. 78:1568-1576.

Moreira, F., C. Risco, M. F. A. Pires, J. D. Ambrose, M. Drost, M. DeLorenzo, and W. W. Thatcher. 2000b. Effect of body condition on reproductive efficiency of lactating dairy cows receiving a timed insemination. Theriogenology 53:1305-1319.

Moreira, F., C. Orlandi, C. A. Risco, R. Mattos, F. Lopes, and W. W. Thatcher. 2001. Effects of presynchronization and bovine somatotropin on pregnancy rates to a timed artificial insemination protocol in lactating dairy cows. J. Dairy Sci. 84:1646-1659. 
Ostrom, M. R., and D. B. Jackson-Smith. 2000. The use and performance of management-intensive rotational grazing among Wisconsin dairy farms in the 1990's. Program on Agricultural Technology Studies (PATS) Research Report No. 8. University of Wisconsin-Extension.

Pursley, J. R., M. O. Mee, and M. C. Wiltbank. 1995. Synchronization of ovulation in dairy cows using $\mathrm{PGF}_{2 \alpha}$ and $\mathrm{GnRH}$. Theriogenology 44:915-923.

Pursley, J. R., M. R. Kosorok, and M. C. Wiltbank. 1997a. Reproductive management of lactating dairy cows using synchronization of ovulation. J. Dairy Sci. 80:301-306.

Pursley, J. R., M. C. Wiltbank, J. S. Stevenson, J. S. Ottobre, H. A. Garverick, and L. L. Anderson. 1997b. Pregnancy rates per artificial insemination for cows and heifers inseminated at a synchronized ovulation or synchronized estrus. J. Dairy Sci. 80:295-300.

Pursley, J. R., P. M. Fricke, H. A. Garverick, D. J. Kesler, J. S. Ottobre, J. S. Stevenson, and M. C. Wiltbank. 2001. Improved fertility in anovulatory, lactating dairy cows treated with exogenous progesterone during Ovsynch. Page 53 in Proc. Midwest Branch ADSA Mtg., Des Moines, IA (Abstr.).

Rasmussen, F. E., M. C. Wiltbank, J. O. Christensen, and R. R. Grummer. 1996. Effects of fenprostalene and estradiol-17-betabenzoate on parturition and retained placenta in dairy cows and heifers. J. Dairy Sci. 79:227-234.

Ruegg, P. L., and R. L. Milton. 1995. Body condition scores of Holstein cows on Prince Edward Island, Canada: relationships with yield, reproductive performance, and disease. J. Dairy Sci. 78:552-564.

SAS/STAT User's Guide, Version 6. 1989. SAS Inst. Inc., Cary, NC.

Sartori, R., J. Haughian, G. J. M. Rosa, R. D. Shaver, and M. C. Wiltbank. 2000. Differences between lactating cows and nulliparous heifers in follicular dynamics, luteal growth, and serum steroid concentrations. J. Dairy Sci. 83(Suppl. 1):212.

Sartori, R., P. M. Fricke, J. C. P. Ferreira, O. J. Ginther, and M. C. Wiltbank. 2001. Follicular deviation and acquisition of ovulatory capacity in bovine follicles. Biol. Reprod. 65:1403-1409.

Savio, J. D., L, Keenan, M. P. Boland, and J. F. Roche. 1988. Pattern of growth of dominant follicles during the estrous cycle of heifers. J. Reprod. Fertil. 83:663-671.
Seguin, B. E., E. M. Convey, and W. D. Oxender. 1976. Effect of gonadotropin-releasing hormone and human chorionic gonadotropin on cows with ovarian follicular cysts. Am. J. Vet. Res. 37:153-157.

Smith, M. W., and J. S. Stevenson. 1995. Fate of the dominant follicle, embryonal survival, and pregnancy rates in dairy cattle treated with prostaglandin $\mathrm{F}_{2 \alpha}$ and progestins in the absence or presence of a functional corpus luteum. J. Anim. Sci. 73:3743-3751.

Staples, C. R., W. W. Thatcher, and J. H. Clark. 1990. Relationship between ovarian activity and energy status during the early postpartum period of high producing dairy cows. J. Dairy Sci. 73:938-947.

Stevenson, J. S., Y. Kobayashi, and K. E. Thompson. 1999. Reproductive performance of dairy cows in various programmed breeding systems including Ovsynch and combinations of gonadotropinreleasing hormone and prostaglandin $\mathrm{F}_{2 \alpha}$. J. Dairy Sci. 82:506515.

Taylor, C., and R. Rajamahendran. 1991. Follicular dynamics, corpus luteum growth, and regression in lactating dairy cattle. Can. J. Anim. Sci. 71:61-68.

Van Cleeff, J., K. L. Macmillan, M. Drost, M. C. Lucy, and W. W. Thatcher. 1996. Effects of administering progesterone at selected intervals after insemination of synchronized heifers on pregnancy rates and resynchronization of returns to service. Theriogenology 46:1117-1130.

Vasconcelos, J. L. M., R. W. Silcox, J. A. Lacerda, J. R. Pursley, and M. C. Wiltbank. 1997. Pregnancy rate, pregnancy loss, and response to heat stress after AI at two different times from ovulation in dairy cows. Biol. Reprod. 56(Suppl. 1):140.(Abstr.)

Vasconcelos, J. L. M., R. W. Silcox, G. J. M. Rosa, J. R. Pursley, and M. C. Wiltbank. 2001. Synchronization rate, size of the ovulatory follicle, and pregnancy rate after synchronization of ovulation beginning on different days of the estrous cycle in lactating dairy cows. Theriogenology 52:1067-1078.

Wildman, E. E., G. M. Jones, P. E. Wagner, H. F. Troutt, Jr., and T. N. Lesch. 1982. A dairy cow body condition scoring system and its relationship to selected production characteristics. J. Dairy Sci. 65:495-501.

Wiltbank, M. C., T. F. Shiao, D. R. Bergfeldt, and O. J. Ginther. 1995. Prostaglandin $\mathrm{F}_{2 \alpha}$ receptors in the early bovine corpus luteum. Biol. Reprod. 52:74-78. 